\title{
THE SERUM LEVELS OF ZINC IN SCHOOL CHILDREN: A CROSSTALK WITH STUNTING AND GIARDIASIS
}

MARWA M. KHALIL ${ }^{1 *}$ AND DOAA M. SULTAN ${ }^{2}$

Department of Public Health, Faculty of Medicine, Zagazig University, Zagazig ${ }^{1}$ and Department of Parasitology, Faculty of Medicine, Mansoura University, Mansoura ${ }^{2}$, Egypt ( ${ }^{*}$ Correspondence: Dr. Khalil email: mdaso4@hotmail.com)

\begin{abstract}
Zinc deficiency is an increasing public health problem. It may be related to compromised neurobehavioral function in children and adolescents. An association between giardiasis and zinc levels in human hosts had been reported. The occurrence of recurrent intestinal infection by Giardia lamblia may reflect a failure to correct an undefined specific nutrient deficiency, for example, the need for adequate zinc repletion. This study estimated the level of serum zinc in a sample of primary school children and to study the associations between it and height for age and giardiasis. A cross section study was carried out on randomly selected primary schools in Dubai and Ajman. They were 500 school children with age range from 6-12 years in Dubai and Ajman. The level of serum zinc, height for age and giardia infection were estimated

The results showed that the prevalence of zinc deficiency was $23 \%$ with no relationship to age or gender. The low serum zinc was significantly associated with stunting and giardiasis. Regression analysis showed that stunting and giardiasis were significant predictors for low serum zinc $(\beta=0.365,0.684$ respectively)
\end{abstract}

Keywords: Serum zinc, primary school children, stunting, giardiasis

\section{Introduction}

Zinc deficiency is an increasing public health problem, with $17.3 \%$ of world's population at risk of inadequate zinc intake (Wessells and Brown, 2012). Evidence of human zinc deficiency began to emerge during 1960s, when cases of zinc-responsive dwarfism and delayed sexual maturation were first reported among Egyptian adolescents (Prasad, 1991). Since then, clinical studies of children with acrodermatitis enteropathica; an inborn error of zinc metabolism that results in poor zinc absorption and, consequently, in severe, secondary zinc deficiency-have ascertained the critical role of zinc in physical growth of humans and normal functioning of the gastrointestinal tract and immune system (Moynahan,1974).

Development of zinc deficiency can be attributed to at least five general causes occurring either in isolation or in combination. These include inadequate intake, increased requirements, malabsorption, increased losses, and impaired utilization (Cuong, 2008).

The children and adolescents are the risky in development of zinc deficiency. The zinc deficiency may be related to compromised neurobehavioral function in them that argue strong need to define extent of zinc deficiency (Maureen, 2003). To date, plasma/serum zinc concentration, dietary intake, and stunting prevalence are the best-known indicators of zinc deficiency (Brown et al, 2004).

There are links between micronutrient deficiencies and immune impairment (Hugues and Kelly, 2006). This evidence is strongest for the trace element Zinc ( $\mathrm{Zn})$. Zn deficiency could be important for susceptibility to infections, since it is essential for numerous immune functions (Ibs and Rink, 2003). Change in zinc level in blood of G. lamblia infected children was reported (Jendryczko et al, 1993; Karakas et al, 2001; Ertan et al, 2002). Besides, Quihui et al. (2010) found that eradication of $G$. lamblia led to a significant improvement in the mean serum $\mathrm{Zn}$ levels six months after treatment in school children. They concluded that giardiasis might be a risk factor for zinc deficiency in schoolchildren from northwestern Mexico. 
G. lamblia causes a generally self-limited clinical illness characterized by diarrhea, abdominal cramps, bloating, weight loss, and malabsorption. However, asymptomatic giardiasis with high reinfection rates occurs frequently, especially in developing countries for reasons that remain obscure (Feng and Xiao, 2011; Cotton, Beatty and Buret, 2011). The occurrence of recurrent intestinal infection by $G$. lamblia required consideration of humoral immune deficiency (Selmi, 2004), and associations between G. lamblia infection and low serum concentrations of zinc were reported in young children (IñigoFigueroa et al, 2015).

This study aimed at estimating the level of serum zinc in a sample of primary school children in United Arab Emirates and to study the associations between zinc status, height for age and giardiasis in the selected sample.

\section{Subjects, Materials and Methods}

Study setting: A cross section study was designed; a sample size of 500 students was calculated according to the estimated sample sizes for surveys of serum zinc concentration by the International Zinc Nutrition Consultative Group (IZiNCG) (Brown et al, 2004). A multi-stage random sample was performed; the emirates of Dubai and Ajman were randomly selected then four primary schools were randomly selected to be included in the study and students in the schools were randomly selected to satisfy the sample size (350 from Dubai and 150 from Ajman). Informed consent was obtained from parents or guardians of participating children.

Height for age: Height was measured (without shoes) using an anthropometric stadiometer to the nearest $0.1 \mathrm{~cm}$. Measures were expressed as height for age (HFA) according to WHO parameters (WHO, 2006). Stunting was defined by values below the $3^{\text {rd }}$ percentile line for HFA.

Biochemical estimation: Three ml. venous blood were collected in sterile tubes. Sera were separated and stored at $-20^{\circ} \mathrm{C}$ until analyzed. Serum zinc concentration was measured by fully automated spectrophotometer (Audit Diagnostic 350). Children were classified as having low or normal serum zinc level according to the suggested lower cut-offs $\left(2.5^{\text {th }}\right.$ percentile $)$ for the assessment of serum zinc concentration in population studies, derived from NHANES II data (Pilch and Senti, 1984). The lower cut off value was $65 \mu \mathrm{mol} / \mathrm{L}$ for children (whatever their gender) less than 10 years old and 66 and $70 \mu \mathrm{mol} / \mathrm{L}$ for girls and boys more than 10 years old respectively.

Parasitological examination: Clean, dry, well labelled specimen containers were distributed to the selected students to deposit their fecal samples. The procedure for introducing the sample into the container was explained to old students and instruction paper was sent home for parents of younger students. Fecal examination was performed by formaldehyde-ether method concentration technique (WHO, 1993).

Statistical analysis: Data were analysed using SPSS 17.0. Continuous numerical variables were displayed as means, while categorical variables were displayed as observed frequencies and proportions. Linear regression was used to estimate the coefficients of the linear equation, involving one or more independent variables that best predict the value of the dependent variable.

\section{Results}

The age range of the students was 6-12 years with a mean of $9.2 \pm 1.8$ years. The boys represented $60 \%$ of the sample size and the girls $40 \%$. The prevalence of low serum zinc in the sample was $23 \%(115 / 500)$. Boys represented about $55 \%$ of the students in the low serum zinc group. There was no statistical significant difference in the level of serum zinc between boys and girls. Older students (10-12 years) represented more than half the students in low serum zinc group. There was no significant difference in the level of serum zinc between the different age groups (Tab. 1). Measuring the students' 
height and comparing it to their age showed that $30.4 \%$ of the students were having HFA lower than the $3^{\text {rd }}$ percentile (stunted). The stunted students $(61.2 \%)$ were having low serum zinc level. There was a significant difference in serum zinc mean concentration between the stunted and normal students. The prevalence of giardiasis was $27.6 \%$. Students with giardiasis showed significant- ly lower serum zinc concentration than noninfected ones (Tab. 2).

The linear regression model for the possible predictors of the serum zinc concentration including the age, gender, stunting and Giardia infection turned to be statistically significant with $\mathrm{R}$ square 0.13 . The stunting and giardiasis (Tab. 3) were the only variables significantly decreasing the level of serum zinc ( $\beta=0.365 \& 0.684$ respectively).

Table 1: Serum zinc level according to gender and age

\begin{tabular}{|l|l|l|l|l|}
\hline \multicolumn{2}{|l|}{ Variable } & Low zinc level & Normal zinc level & $\mathbf{X}^{\mathbf{2}}, \mathbf{P}$ \\
\hline \multirow{2}{*}{ Gender } & Boys & $63(54.8 \%)$ & $237(61.6 \%)$ & $\mathrm{X}^{2}=1.69$ \\
\cline { 2 - 5 } & Girls & $52(45.2 \%)$ & $148(38.4 \%)$ & $\mathrm{P}>0.05$ \\
\hline \multirow{2}{*}{ Age } & 6-9 years & $54(47 \%)$ & $200(51.9 \%)$ & $\mathrm{X}^{2}=0.88$ \\
\cline { 2 - 5 } & $10-12$ years & $61(53 \%)$ & $185(48.1 \%)$ & $\mathrm{P}>0.05$ \\
\hline
\end{tabular}

Table 2: Mean zinc level in stunting and giardiasis

\begin{tabular}{|c|c|c|c|c|}
\hline \multicolumn{2}{|l|}{ Variable } & \multicolumn{2}{|c|}{ Zinc concentration $(\mu \mathrm{mol} / \mathrm{L})$} & \multirow[t]{2}{*}{$\mathrm{t}, \mathrm{P}$} \\
\hline & & $\mathrm{X}^{\prime}$ & SD & \\
\hline \multirow[t]{2}{*}{ Stunting } & Yes & 63.4 & 4.4 & \multirow{2}{*}{$\begin{array}{l}\mathrm{t}=7.41 \\
\mathrm{P}<0.05\end{array}$} \\
\hline & No & 66.1 & 3.3 & \\
\hline \multirow[t]{2}{*}{ Giardiasis } & Yes & 63.8 & 4.3 & \multirow{2}{*}{$\begin{array}{l}\mathrm{t}=5.38 \\
\mathrm{P}<0.05\end{array}$} \\
\hline & No & 65.8 & 3.5 & \\
\hline
\end{tabular}

Table 3: Predictors of serum zinc concentration: Linear regression model

\begin{tabular}{|l|c|c|c|}
\hline Model & Standardized coefficient $(\beta)$ & $\mathrm{t}$ & $\mathrm{P}$ \\
\hline (Constant) & & 120.211 & .000 \\
\hline Stunting (HFA) & .365 & 3.466 & .001 \\
\hline Giardiasis & .684 & 6.333 & .000 \\
\hline Gender & .086 & 1.361 & .174 \\
\hline Age & .024 & .394 & .694 \\
\hline
\end{tabular}

\section{Discussion}

The current study evaluates the level of serum zinc in a sample of primary school children in Dubai and Ajman and its relation with giardiasis infection and stunting.

Nowadays, there is growing interest in dietary factors, in particular micronutrients, from the perspective of disease pathogenesis and potential for treatment. Results of field and laboratory studies provide convincing evidence that micronutrient deficiencies contribute to the mortality and morbidity of infectious diseases (Walker and Black, 2004; Wolfgang and Harold, 2006). Zinc is an essential trace element in the diets of humans for optimal health and growth (Prasad, 1991). It is required for the genetic makeup of every cell and considered as an absolute requirement for all biologic reproduction hence; widespread sub optimal zinc nutrient constitutes a notable health risk for children in terms of growth and development (Berg and Shi, 1996).

In the present study, the prevalence of low serum zinc to be $23 \%$. The prevalence and burden of zinc deficiency was quite different worldwide, according to disease control priorities in developing countries (2006), the prevalence of zinc deficiency in the Middle East was about 46\% (Dehghani et al, 2011). Studies in primary school children found a prevalence of $0.7 \%$ in China (Qin et al, 2009 ) and $28.1 \%$ in Iran (Fesharakinia et al, 2009). Also, low serum zinc concentration $(57 \%)$ was found among 6-13 years old school children in North-East Thailand (Thurlow et al, 2006). In Mexican schoolage children (below 12 years), zinc deficiency based on serum zinc was $19-24 \%$ (Villalpando et al, 2003). 
The present results agreed with Arvanitidou (2007) in Greece and with Fesharakinia et al. (2009) as there was no significant relationship between sex and serum zinc level but low serum zinc was slightly more among boys. On the other hand, Qin et al. (2009) and Gibson et al. (2007) found that boys had significantly lower serum zinc level.

While the aetiology of stunting is complex, inadequate nutrition and infection are among factors thought to play major roles in reducing a child's height-for-age (Mikhail et $a l, 2013)$. Stunting was a functional indicator of population zinc status (Fischer and Black, 2007). This was marked in the present study where the prevalence of stunting was significantly higher in zinc deficient children compared to those with normal zinc level. Impaired linear growth proved to be a prominent feature of zinc deficiency among children in both developed and developing countries (Aggett, 1995; Hambidge, 2000; Brown et al, 2002; Gibson et al, 2007)

The level of zinc in blood of $G$. lamblia infected children decreased during giardiasis infection (Berkman, 2003; Demirci, 2003; Abou-Shady et al, 2011). This agreed with the present study, as children with giardiasis was significantly associated with lower mean serum zinc. This could be related to the fact that giardiasis resulted in sequestration of zinc in the liver (Liu et al, 2012), which led to decrease circulating levels of zinc and reduced zinc as well in other tissues.

In Egypt giardiasis as an endemic protozoan causing diarrhoea was reported in nearly all governorates (El-Gebaly et al, 2012) particularly among children (El-Sherbini et al, 2008) with pathological grading related to Giardia genotypes (Rizk et al, 2004).

Eldash et al. (2013) stated that recurrent abdominal pain (RAP) affected $10-20 \%$ of school-aged children and that Helicobacter pylori and Giardia intestinalis were reported among organic causes of RAP, with different prevalence particularly in developing countries as one of the commonest associated diseases causing agents. They evaluated H. pylori and G. intestinalis co-infection in RAP Egyptian among 90 children and 90 cross matched healthy controls. They concluded that incidence of $H$. pylori infection among cases was higher among age group above 5 years $(p=0.001)$, as a significant predictor for RAP. The association of $H$. pylori and G. intestinalis was among 36 $(40.0 \%)$ patients and $11(12.2 \%)$ controls with a significant difference $(p<0.001)$. They added that in treatment of $\mathrm{H}$. pylori giardiasis must be treated. Helmy et al. (2014) stated that the risk of zoonotic infection emanating from ruminants even in high prevalence areas is negligible. Genetic characterization indicated a predominant anthropogenic cycle of infection within the pediatric population studied. Integration of sequence typing data with information on geographic origins of samples allows parasite sub-population tracing using current typing tools. Abdel-Hafeez et al. (2013) found that the percentage of zoonotic Cryptosporidium spp., Entamoeba histolytica/dispar, Giardia lamblia, and Bla-stocystis sp. was significantly lower in brea-st-fed infants than that in non-breast-fed infants. There were significant positive associations between the serum levels of IgE and TNF- $\alpha$ and the intensity of parasite infection in the breast-fed group. They concluded that breast-feeding has an attenuating effect on the rate and intensity of parasite infection.

\section{Conclusion}

The current study proved that zinc deficiency in the school children in Dubai and Ajman. Stunting was associated giardiasis infection. Considering the critical roles of adequate zinc in supporting normal growth and development, preventing morbidity from common infections, and possibly reducing child mortality, it is recommended to target this circle and break it up.

The nutritional education and screening programs are advised to improve the general nutritional status of giardiasis infected chil- 
dren which would be reflected on their cognitive function.

\section{References}

Abdel-Hafeez, EH, Belal, US, Abdellatif, MZ, Naoi, K, Norose, K, 2013: Breast-feeding protects infantile diarrhea caused by intestinal protozoan infections. Korean J. Parasitol. 51, 5:51924

Abou-Shady O, El Raziky, M.S, Zaki M.M and Mohamed R.K, 2011: Impact of Giardia lamblia on growth, serum levels of zinc, copper, and iron in Egyptian children. Biol. Trace Elem. Res.140:1-6.

Aggett PJ, 1995: Zinc and human health. Nutr. Rev. 53: S16-22

Arvanitidou V, Voskaki I, Tripsianis G, Athanasopoulou $\mathrm{H}$, Tsalkidis A, Filippidis $\mathbf{S}$, Schulpis K, Androulakis I, 2007: Serum copper \& zinc concentrations in healthy children aged 314 years in Greece. Biol. Trace Elem. Res. 115: 1-12.

Berg, JM, Shi, Y, 1996: The galvanization of biology: A growing appreciation for the roles of zinc. Science 127:1333-8.

Berkman DS, Lescano AG, Gilman RH, López SL, 2003: Effects of stunting, diarrhoeal disease, and parasitic infection during infancy on cognition in late childhood: A follow-up study. Lancet.359: 564-71.

Brown, KH, Peerson, JM, Rivera, J, Allen, LH, 2002: Effect of supplemental zinc on the growth and serum zinc concentrations of prepubertal children: a meta-analysis of randomized controlled trials. Am. J. Clin. Nutr. 75:1062-71.

Brown, KH, Rivera, JA, Bhutta, Z, Gibson, RS, King, JC, et al, 2004: International zinc nutrition consultative group (izincg) technical document \#1: Assessment of the risk of zinc deficiency in populations and options for its control. Food Nutr. Bull. 25: S99-203.

Cotton, AJ, Beatty, JK, Buret, AG, 2011: Host parasite interactions and pathophysiology in Giardia infections. Int. J. Parasitol. 41: 925-32.

Cuong, DT, 2008: Advances of zinc in health research. In: Micronutrients and Health Research. By Yoshida, T, Nova Science Publishers Inc.

Dehghani, SM, Katibeh, P, Haghighat, M, Moravej, H, Asadi, S, 2011: Prevalence of zinc deficiency in 3-18 years old children in ShirazIran. Iran Red Crescent Med J. 13, 1:4-8.
Demirci, M, Delibas, N, Altuntas, I, Oktem, F, Yonden, Z, 2003: Serum iron, zinc and copper levels and lipid peroxidation in the children with chronic giardiasis. J. Hlth. Popul. Nutr. 21:72-5.

Eldash, HH, Bekhit, OE, Algameel, AA, 2013: Impact of Helicobacter pylori-giardiasis coinfection on children with recurrent abdominal pain. J. Egypt. Soc. Parasitol. 43, 2:509-16

El-Gebaly, NS, Halawa, EF, Moussa, HM, Rabia, I, Abu-Zekry, M, 2012: Saliva and sera IgA and IgG in Egyptian Giardia-infected children. Parasitol. Res. 111, 2:571-5.

El-Sherbini, GT, Aboul Noor, MF, Hegazi, M M, 2008: Parasitiosis in handicapped children in an Egyptian blind asylum. J. Egypt. Soc. Parasitol. 38, 1:319-26.

Ertan, P, Yereli, K, Kurt, O, Balcioglu, I, Onag, A, 2002: Serological levels of zinc, copper and iron elements among Giardia lamblia infected children in Turkey. Pediatr. Int. 44: 2868.

Feng, Y, Xiao, L, 2011: Zoonotic potential and molecular epidemiology of Giardia species and giardiasis. Clin. Microbiol. Rev. 24:110-40.

Fesharakinia, A, Zarban, A, Gholam, R, 2009: Prevalence of zinc deficiency in elementary school children of south Khorasan Province (East Iran). Iran J. Pediatr. 19, 3:249-54

Fischer Walker, CL, Black, RE, 2007: Functional indicators for assessing zinc deficiency. Food Nutr. Bull. 28:S454-79

Gibson, RS, Manger, MS, Krittaphol, W, Pongcharoen, T, Gowachirapant, S, et al, 2007: Does zinc deficiency play a role in stunting among primary school children in NE Thailand? Br. J. Nutr. 97:167-75.

Hambidge, KM, 2000: Human zinc deficiency. J. Nutr. 130: S 1344-9

Helmy, YA, Klotz, C, Wilking, H, Krücken, J, Nöckler, K, et al, 2014: Epidemiology of Giardia duodenalis infection in ruminant livestock and children in the Ismailia province of Egypt: insights by genetic characterization. Parasit Vectors $11 ; 7: 321-8$

Hugues, S, Kelly, P, 2006: Interactions of malnutrition and immune impairment, with specific reference to immunity against parasites. Parasite Immunol. 28: 577-88.

Ibs, KH, Rink, L, 2003: Zinc-altered immune function. J. Nutr. 133:1452-6.

Iñigo-Figueroa, G, Méndez-Estrada, RO, Quiui-Cota, L, Velásquez-Contreras, CA, Garib- 
ay-Escobar A, et al, 2013: Effects of dietary zinc manipulation on growth performance, zinc status and immune response during Giardia lamblia infection: A study in cd-1 mice. Nutrients 5, 9:3447-60

Jendryczko, A, Sodowska, H, Drózdz, M, 1993: Zinc deficiency in children infected with Giardia lamblia. Wiad. Lek. 46:32-35.

Karakas, Z, Demirel, N, Tarakcioglu, M, Mete, N, 2001: Serum zinc and copper levels in southeastern Turkish children with giardiasis or amebiasis. Biol. Trace Elem. Res. 84:11-18.

Liu Janet Z, Jellbauer, Stefan , Poe Adam J, et al, 2012: Zinc sequestration by the neutrophil protein calprotectin enhances salmonella growth in the inflamed gut. Cell Host Microbe 11, 3:227-39

Maureen M. Black, 2003: The Evidence Linking Zinc Deficiency with Children's Cognitive and Motor Functioning. J. Nutr. 133 (5): 1473S$1476 \mathrm{~S}$

Mikhail, WZA, Sobhy, HM, El-Sayed, HH, Khairy, SA, Abu Salem, HYH, et al, 2013: Effect of nutritional status on growth pattern of stunted preschool children in Egypt. Acad. J. Nutr. 2, 1:1-9

Moynahan, EJ, 1974: Letter: Acrodermatitis enteropathica: a lethal inherited human zincdeficiency disorder. Lancet 2:399-400.

Pilch, SM, Senti, FR, 1984: Assessment of the zinc nutritional status of the US population based on data collected in the second National Health and Nutrition Examination Survey, 19761980. Bethesda, MD: Life Sciences Research Office, Federation of American Societies for Experimental Biology.

Prasad, AS, 1991: Discovery of human zinc deficiency and studies in an experimental human model. Am. J. Clin. Nutr. 53:403-12.

Qin, Y, Melse-Boonstra, A, Zhao, J, Wu, M, Hu, X, et al, 2009: Stunting and zinc deficiency among primary school children in rural areas with low soil zinc concentrations in Jiangsu Province, China. Asia Pac. J. Clin. Nutr. 18, 1: 15-21

Quihui, L, Morales, GG, Méndez, RO, Leyva, JG, Esparza, J, et al, 2010: Could giardiasis be a risk factor for low zinc status in schoolchildren from northwestern Mexico? a cross-sectional study with longitudinal follow up. BMC Pub. Hlth. 10:85-92.

Risk, H, el-Shazly, AM, Soliman, M, Mohamad, AA, Morsy ATA, 2004: Genotyping of human giardiasis in relation to anti-Giardia secretory IgA and mucosal histopathology. J. Egypt. Soc. Parasitol. 34, 2:471-81.

Selmi, C, Invernizzi, P, Zuin, M, Ansari, AA, Gershwin, ME, 2004: Evaluation of the Immune function in the nutritionally at-risk patient. In: Handbook of Nutrition and Immunity, $1^{\text {st }}$ ed.; Vol. 1, Gershwin, ME, Nestel, P, Keen, CL, eds.; Humana Press: Totowa, NJ, USA.

Thurlow, RA, Winichagoon, P, Pongcharoen, T, Gowachirapant, S, Boonpraderm, A, et al, 2006: Risk of zinc, iodine and other micronutrient deficiencies among school children in north east Thailand. Eur. J. Clin. Nutr. 60:623-32.

Villalpando, S, Garcia-Guerra, A, Ramirez, CI, Mejia-Rodriguez, F, Matute, G, et al, 2003: Iron, zinc and iodide status in Mexican children under 12 years and women 12-49 years of age: A probabilistic national survey. Salud. Publ. Mex. 45:S520-9.

Walker, CF, Black, RE, 2004: Zinc and the risk for infectious disease. Ann. Rev. Nutr. 24: 255-75

Wessells, KR, Brown, KH, 2012: Estimating the global prevalence of zinc deficiency: Results based on zinc availability in national food supplies and the prevalence of stunting. PLoS One 7, 11:e505-68.

Wolfgang, M, Harold, HS, 2006: Zinc requirements and the risks and benefits of zinc supplementation. J. Trace Elem. Med. Biol., 20, 1: 3-18

WHO, 1993: Basic Laboratory Methods in Medical Parasitology. Geneva, Switzerland.

WHO/MGR, 2006: Methods and Development. Geneva: Multicenter growth reference Study group. WHO child growth standards, length/heiight-for-age, weight-for-age, weight-for-length, weight-for-height, body mass index-for-age. Geneva, Switzerland. 